Research Article $\mid$ Internal Medicine | Medical Education

\title{
Evaluation of the Implementation of Personal Protective Behaviors and the Interventions Made in Fighting Against COVID-19 Through the View of a University Staff
}

\author{
Inci Arıkan ${ }^{* *}$ (D), Barış Kılıç Demir ${ }^{2}$ (D)
}

\begin{abstract}
The objective of this study was to evaluate the application status of Personal Protective Behaviors (PPB) in the fight against COVID-19 among the employees of an institution and the interventions that may be effective for maintaining PPB.

Materials and Methods. In this descriptive study, the interviews were made with each participant to answer the structured questions. In the interviews, we questioned whether PPB were applied correctly and which interventions could be effective in maintaining PPB.

Results. PPB were correctly applied by more than half of 101 people who participated in the study. When considering the distribution of responses to which interventions to maintain PPB were effective, the first three places were arranged as follows: education, coercion-punishment and treatment/death of a relative due to COVID-19. The face mask use and compliance with social distancing were found to be the most important and applied PPB.

Conclusions. The participants stated that health education models should be used at the beginning of different intervention types and supported with fines and restrictions, if necessary. In addition, the positive detection of COVID-19 in the close environment and the experience of the treatment process were found to be effective in taking precautions.
\end{abstract}

Keywords

COVID-19; Fighting; Interventions; Protective Behaviors; Staff

${ }^{1}$ Department of Public Health, Medical Faculty of Kütahya Health Sciences University, Kütahya, Turkey

${ }^{2}$ Department of Psychiatry, Health Sciences University, Adana City Training and Research Hospital, Adana, Turkey

*Corresponding author: inci.arikan@ksbu.edu.tr

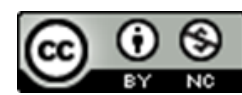

Copyright @ínci Arıkan, Barış Kılıç Demir, 2021

\section{Problem statement and analysis of the latest research}

The health behaviors people will show in the face of an epidemic threat are important in reducing the spread rate of the epidemic. Decisions taken by health authorities, measures such as mandatory quarantines and curfews are effective in pandemic management. However, considering the negative effects on mental health by increasing anxiety among people and the heavy burden on the global economy, it does not seem possible to apply such measures for a long time [1-3]. In this context, it is necessary for individuals to have and maintain individual behaviors to protect themselves from the disease [4-
7].

The behaviors in the fight against COVID-19 listed below are called Personal Protective Behaviors (PPB). They include correct use and disposal of the face mask; reducing touching the face with hands; washing/disinfecting the hands frequently; cleaning/disinfecting the surfaces and objects; staying at home; complying with social distancing. The full implementation of PPB is important in effective combating the COVID-19 pandemic. In addition, it is necessary and of high priority for individuals to get support with guidance and health education in order to increase their adaptation to these behaviors [3-7]. Government policies and action plans should be based on individuals' behaviors and perceptions, 
and interventions should be formulated accordingly [5-10].

The following issues should be emphasized in interventions: to adopt measures focused on health education; to convince people to practice them; to direct people to use health services correctly; to make decisions for health protection. It should be supported by social media, communication tools and environmental regulations as well. However, intervention studies investigating the effectiveness of PPB are not yet sufficient. In our study, the interventions that can be effective for the correct application and maintenance of PPB in the fight against COVID-19 are summarized under 8 headings by scanning the literature based on individual behavioral models [4, 8-10].

The objective of this study was to evaluate the application status of PPB in the fight against COVID-19 among the employees of an institution and the interventions that may be effective for maintaining PPB.

\section{Materials and Methods}

\section{Study Design}

Since the descriptive study was aimed to reach all the staff (except for academic staff; $\mathrm{N}$ : 115) working at a university between August and September 2020, the sample calculation was not made. The study was completed with 101 people (88\% participation rate) who accepted to participate in the study. Permissions from the local ethics committee and institution were obtained.

\section{Data Collection Tools}

The first part of the questionnaire prepared included the sociodemographic characteristics of the participants, and the second part included questions about COVID-19. For the answers to the structured questions, interviews, not exceeding $15 \mathrm{~min}$ utes, were held with each person. In these interviews, regarding whether PPB made to protect against COVID-19 are applied correctly, the most important behaviors were asked. We questioned which interventions might be effective in maintaining these behaviors. The interventions mentioned were classified under 8 headings based on the following individual behavior models: West et al. study, the Health Belief Model, social cognitive theory, social network theory [4, 8-10] (Table 1). We added "the relative has been treated for COVID-19 or died" to these types of interventions.

\section{Statistical Analysis}

Data were analyzed using the IBM SPSS Statistics Premium Gradpack 27.0 software package program. The suitability of variables to normal distribution was evaluated using the Kolmogorov-Smirnov test. Descriptive data were presented as numbers, percentages and the Chi-square test was used for statistical evaluation. Monte Carlo correction was made from Exact tests where the expected frequencies were less than 5 in more than $25 \%$ of the table cells. The level of significance was accepted as $\mathrm{p} \leq 0.05$.

\section{Results}

Out of 101 people included in our study, there were 41 (40.6\%) females. The average participants' age was $36.12 \pm 7.75$ (min: 22 - max: 61) years and $68.3 \%$ of them were married. Among them, $10.9 \%$ of the participants had primary and secondary education; $25.7 \%$ of the participants completed high school; $36.6 \%$ of the participants were undergraduate; $26.7 \%$ of the participants had graduate education level; $80.2 \%$ of the participants were office employees, $14 \%$ of the participants were cleaning personnel; $6 \%$ of the participants were security guards.

When examining the correct PPB application by the participants, it was determined that the behaviors such as cleaning the surfaces and belongings, staying at home and complying with social distancing were more accurately applied by

Table 1. Types of intervention and content framework.

\begin{tabular}{ll}
\hline Types of intervention & Content framework \\
\hline 1. Education & $\begin{array}{l}\text { Guidance should be given, taking into account the changing educational } \\
\text { level and conditions. } \\
\text { 2. Persuasion }\end{array}$ \\
$\begin{array}{l}\text { Focus on anxiety and sense of responsibility towards others by ensuring } \\
\text { active participation. }\end{array}$ \\
3. Encouragement & $\begin{array}{l}\text { Focus should be on the using social reward and thanking those who do } \\
\text { the behavior. } \\
\text { These practices should be directed to the person's behavior and given } \\
\text { quickly on the spot. }\end{array}$ \\
4. Coercion - punishment & $\begin{array}{l}\text { How and when to do what behavior and how to correct it should be taught } \\
\text { by practicing. } \\
\text { Boundaries must be clear and acceptable to all people. } \\
\text { Physical arrangements, indoors and outdoors, that support and encourage } \\
\text { correct behavior, should include markings. }\end{array}$ \\
6. Restriction & $\begin{array}{l}\text { Implementation of the correct behavior should be demonstrated by adapt- } \\
\text { ing it to the cultural and ethnic structure of the target audience. }\end{array}$ \\
7. Environmental regulation &
\end{tabular}


Table 2. Comparison of the percentage of correct PPB application depending on gender.

\begin{tabular}{|c|c|c|c|c|}
\hline \multirow{2}{*}{ PPB } & \multicolumn{2}{|c|}{ Those who applied the PPB correctly } & \multirow[b]{2}{*}{ Total, $\mathrm{n}(\%)$} & \multirow[b]{2}{*}{$\mathrm{p}$} \\
\hline & Males, $\mathrm{n}(\%)$ & Females, $\mathrm{n}(\%)$ & & \\
\hline Correct use and disposal of the face mask & $43(71.7)$ & $32(78.1)$ & $75(74.3)$ & 0.471 \\
\hline Reducing the touching of the face with hands & $22(36.7)$ & $21(51.2)$ & $43(42.6)$ & 0.146 \\
\hline Washing/disinfecting the hands frequently & $36(76.7)$ & $46(87.7)$ & $82(81.2)$ & 0.200 \\
\hline Cleaning/disinfecting the surfaces and objects & $19(48.3)$ & $39(70.7)$ & $58(57.4)$ & 0.025 \\
\hline Staying at home & $17(28.3)$ & $28(68.3)$ & $45(44.6)$ & 0.000 \\
\hline Complying with social distancing & $38(63.3)$ & $37(90.2)$ & $75(74.3)$ & 0.002 \\
\hline
\end{tabular}

Table 3. Comparison of the percentage of correct PPB application depending on the educational status.

\begin{tabular}{lccccc}
\hline \multicolumn{1}{c}{ PPB } & \multicolumn{4}{c}{ Educational status, n (\%) } \\
\cline { 2 - 5 } & $\begin{array}{c}\text { Primary- } \\
\text { secondary } \\
\text { school }\end{array}$ & High school & Undergraduate & $\begin{array}{c}\text { Master's } \\
\text { degree }\end{array}$ & $\mathrm{p}$ \\
\hline Correct use and disposal of the face mask & $7(63.6)$ & $13(70.0)$ & $35(81.6)$ & $20(74.1)$ & 0.058 \\
Reducing the touching of the face with hands & $7(63.6)$ & $8(30.8)$ & $16(43.2)$ & $12(44.4)$ & 0.459 \\
Washing/disinfecting the hands frequently & $8(72.7)$ & $18(69.2)$ & $33(89.2)$ & $23(85.2)$ & 0.069 \\
Cleaning/disinfecting the surfaces and objects & $7(63.6)$ & $18(69.2)$ & $18(48.6)$ & $15(55.6)$ & 0.175 \\
Staying at home & $7(63.6)$ & $11(42.3)$ & $17(45.9)$ & $10(37.0)$ & 0.142 \\
Complying with social distancing & $8(72.7)$ & $16(61.5)$ & $28(75.7)$ & $23(85.2)$ & 0.078 \\
\hline
\end{tabular}

women. The following PPB were applied correctly by more than half of all participants: frequent hand washing, use of the face masks, compliance with social distancing and cleaning the surfaces and belongings (Table 2).

No statistically significant difference was found between the correct PPB application and the educational status (Table 3).

When looking at the distribution of responses to which interventions to maintain PPB are effective, the first three places were arranged as follows: education, coercion-punishment and treatment/death of a relative due to COVID-19 (Table 4).

Table 4. Distribution of responses given to which interventions are effective for maintaining PPB.

\begin{tabular}{lcc}
\hline Types of intervention & $\mathrm{N}^{*}$ & $\%$ \\
\hline Education & 40 & 28.6 \\
Convincement & 17 & 12.1 \\
Encouragement & 5 & 3.6 \\
Coercion - punishment & 38 & 27.1 \\
Organizing the environment & 5 & 3.6 \\
Relatives receiving COVID treatment/dying & 35 & 25.0 \\
\hline Note: * multiple answers are included.
\end{tabular}

\section{Discussion}

Considering the infectivity of communicable diseases, their virulence and clinical course, the number of people affected, direct and indirect costs associated with such diseases, the prevention of the development and spread of infectious diseases is a priority in their combating. When studying the epidemiology of all epidemics to date, it has been seen that the transmission route is a factor that changes the course of the epidemic [11]. Specifically, the example of COVID-19 has shown us that some interventions are necessary to be carried out to take individual precautions and implement protective behaviors in the fight against droplet-borne diseases. Using health promotion strategies in these interventions is the right approach. Individual behavioral patterns can play an important role in guiding our societies in these challenging times. Effective health education and communication are key factors in fighting the pandemic [12]. However, intervention studies investigating the effectiveness of trainings and PPB for COVID-19 are not yet sufficient $[4,11,12]$.

In our study, the relationship between the use of 6 PPB against COVID-19 and some sociodemographic variables was examined. At the same time, the opinions of the participants about the types of interventions based on individual behavioral models were taken.

More than half of the participants were found to correctly apply the behaviors of using masks, complying with social distancing, washing hands frequently and disinfecting the surfaces and objects. In addition, these behaviors were observed to be applied more correctly by women. There was no statistical difference between age, education level and PPB application status.

In a review analyzing the effect of gender on health risk behaviors, compliance with daily hygienic behavior has been reported to be better in women than men [13]. Guzek et al. stated that PPB against COVID-19 were higher in women [14]. 
The findings of our study supported these results.

During the pandemic, the extensive use of social media and communication resources increased society's anxiety and stress, and the information from these sources played a role in the development of situational awareness. Some studies have been stated that individual situational awareness increased in parallel with the adoption and application of PPB [15-17].

In our study, the participants were aware that the working environment is crowded, they knew that COVID-19 is transmitted by air, used the face masks, and paid attention to social distancing. However, while paying attention to common areas within the institution, we can say that people working in the same room were less compliant with these rules. In addition, we questioned which of the intervention types we created for the correct and continuous implementation of PPB would be more effective. More than $25 \%$ of the participants responded to education, punishment-coercion and death of a relative. Responses to encourage and organize the environment were in last place.

Undoubtedly, training is one of the interventions required for the correct PPB application [12]. Guidance should be given, considering the people's education level, ethnicity and living conditions. Punishments, on the other hand, should be directed towards the person's behavior and given quickly on the spot [4]. The COVID-19 pandemic has shown us that everyone is primarily responsible for their own health and we must change our lifestyle to prevent transmission. We know that if the PPB is not applied correctly, we will face some restrictions and penalties. These measures should be taken in emergency situations such as a pandemic for public health. The central point of social network theory and structures that shape the effects of other determinants are as follows: providing physical, emotional and financial social support by family, colleagues and people who make up our immediate environment [9, 10, 17-19].

Some studies have reported that during the pandemic we are in, people are more concerned about their own health, as well as their family health and the support from the immediate environment facilitates PPB applications [2, 20-22]. The striking point in our study was that in case of correct and continuous PPB application, the response of the relative receiving COVID-19 treatment/dying was as effective as education and punishment-coercion. The upsetting side of this situation is that we take precautions after our relatives are sick. Environmental regulations, including physical signs indoors and outdoors, that support/encourage correct behavior are required. In addition, thanks to those who do behavior, encouragement based on using social reward can be used to ensure behavior change. Responses to regulate and encourage the environment were ranked lower in our study. The fact that we are experiencing the $6^{\text {th }}$ month of the pandemic in our country and that environmental regulations have been set may have caused these answers. If we were in the early stages of the pandemic, we would expect more responses about environmental regulation and people incentives.
This study had several limitations. Firstly, the sample group was small. Secondly, the data obtained depended on the participants' own statements. Since we examined the PPB application status among the personnel working in an institution, the results are not generalized to the whole society. Therefore, we believe that our results should be supported by prospective studies with a larger population. However, information for future intervention studies has been provided and it can be said that the situation has been evaluated. In addition, we consider holding face-to-face meetings with the participants as an opportunity, as corporate health education and awareness about COVID-19 have been provided.

\section{Conclusions}

The most important and applied PPB, namely face mask use and compliance with social distancing were determined. The participants stated that health education models should be used at the beginning of different intervention types and supported with fines and restrictions, if necessary. In addition, the positive detection of COVID-19 in the close environment and the experience of the treatment process were found to be effective in taking precautions. Due to the nature of the disease, people's perceptions and beliefs are known to affect their response to the disease and health behaviors. Individuals should evaluate their situation, be motivated, adopt the importance of PPB and make them as a habit. Thus, acquired individual behavioral changes can results in changes that will affect the whole society.

\section{Ethical Statement}

Permission to conduct this study was provided by the Ethics Committee of Kütahya Health Sciences University in July 2020 (Ref No. 2020/12-15). All procedures contributing to this work comply with the ethical standards of the relevant national and institutional guidelines and the Declaration of Helsinki.

\section{Informed Consent}

Before the study, all the participants were verbally informed.

\section{Conflict of Interest}

The authors declare no potential conflicts of interest with respect to the research, authorship, and/or publication of this article.

\section{Financial Disclosure}

The authors received no financial support for the research, authorship, and/or publication of this article.

\section{References}

[1] Cowling BJ, Ali ST, Ng TWY, Tsang TK, Li JCM, Fong MW, et al. Impact assessment of nonpharmaceutical interventions against coronavirus 
disease 2019 and influenza in Hong Kong: an observational study. The Lancet Public Health [Internet]. 2020;5(5):e279-e288. Available from: https://doi.org/10.1016/S2468-2667(20)30090-6

[2] Yuan S, Liao Z, Huang H, Jiang B, Zhang X, Wang Y, et al. Comparison of the indicators of psychological stress in the population of Hubei Province and non-endemic provinces in China during two weeks during the coronavirus disease 2019 (COVID19) outbreak in February 2020. Medical Science Monitor [Internet]. 2020;26:e923767. Available from: https://doi.org/10.12659/MSM.923767

[3] Marcinko D, Jakovljevic M, Jaksic N, Bjedov S, Mindoljevic Drakulic A. The importance of psychodynamic approach during COVID-19 pandemic. Psychiatria Danubina [Internet]. 2020;32(1):15-21. Available from: https://doi.org/10.24869/psyd.2020.15

[4] West R, Michie S, Rubin GJ, Amlôt R. Applying principles of behaviour change to reduce SARSCoV-2 transmission. Nature Human Behaviour [Internet]. 2020;4(5):451-459. Available from: https://doi.org/10.1038/s41562-020-0887-9

[5] World Health Organization (WHO). WHO announces COVID-19 outbreak a pandemic. Available from: http://www.euro.who.int/en/healthtopics/health-emergencies/coronavirus-covid-

19/news/news/2020/3/who-announces-covid-19outbreak-a-pandemic

[6] Centers for Disease Control and Prevention (CDC). Using personal protective equipment (PPE). Available from: https://www.cdc.gov/coronavirus/2019ncov/hcp/using-ppe.html

[7] World Health Organization (WHO). Rational use of personal protective equipment for coronavirus disease (COVID-19) and considerations during severe shortages. Available from: https://www.who.int/publications/i/item/rational-use-ofpersonal-protective-equipment-for-coronavirus-disease(covid-19)-and-considerations-during-severe-shortages

[8] Demirbilek Y, Pehlivantürk G, Özgüler ZO, Meşe EA. COVID-19 outbreak control, example of Ministry of Health of Turkey. Turk J Med Sci. 2020;50:489-494. Available from: https://doi.org/10.3906/sag-2004-187

[9] Bavel JJV, Baicker K, Boggio PS, Capraro V, Cichocka A, Cikara M, et al. Using social and behavioural science to support COVID-19 pandemic response. Nature Human Behaviour [Internet]. 2020;4(5):460-471. Available from: https://doi.org/10.1038/s41562-020-0884-z
[10] Balkhi F, Nasir A, Zehra A, Riaz R. Psychological and behavioral response to the coronavirus (COVID-19) pandemic. Cureus [Internet]. 2020;12(5):e7923. Available from: https://doi.org/10.7759/cureus.7923

[11] Antonovics J, Wilson AJ, Forbes MR, Hauffe HC, Kallio ER, Leggett HC, et al. The evolution of transmission mode. Philosophical Transactions of the Royal Society B: Biological Sciences [Internet]. 2017;372(1719):20160083. Available from: https://doi.org/10.1098/rstb.2016.0083

[12] Finset A, Bosworth H, Butow P, Gulbrandsen P, Hulsman RL, Pieterse AH, et al. Effective health communication - a key factor in fighting the COVID-19 pandemic. Patient Education and Counseling [Internet]. 2020;103(5):873-876. Available from: https://doi.org/10.1016/j.pec.2020.03.027

[13] Hiller J, Schatz K, Drexler H. Gender influence on health and risk behavior in primary prevention: a systematic review. Journal of Public Health [Internet]. 2017;25(4):339-349. Available from: https://doi.org/10.1007/s10389-017-0798-z

[14] Guzek D, Skolmowska D, Glabska D. Analysis of gender-dependent personal protective behaviors in a national sample: polish adolescents' COVID-19 experience (PLACE-19) study. International Journal of Environmental Research and Public Health [Internet]. 2020 Aug 10;17(16):5770. Available from: https://doi.org/10.3390/ijerph17165770

[15] Garfin DR, Silver RC, Holman EA. The novel coronavirus (COVID-2019) outbreak: amplification of public health consequences by media exposure. Health Psychology [Internet]. 2020;39(5):355-357. Available from: https://doi.org/10.1037/hea0000875

[16] Qazi A, Tamjidyamcholo A, Raj RG, Hardaker G, Standing C. Assessing consumers' satisfaction and expectations through online opinions: expectation and disconfirmation approach. Computers in Human Behavior [Internet]. 2017;75:450-460. Available from: https://doi.org/10.1016/j.chb.2017.05.025

[17] Đogaš Z, Lušić Kalcina L, Pavlinac Dodig I, Demirović S, Madirazza K, Valić M, et al. The effect of COVID-19 lockdown on lifestyle and mood in Croatian general population: a cross-sectional study. Croatian Medical Journal [Internet]. 2020;61(4):309-318. Available from: https://doi.org/10.3325/cmj.2020.61.309

[18] Jack L, Grim M, Gross T, Lynch S, Mclin C. Theory in health promotion programs. In: Fertman CI, Allensworth DD, editors. Health Promotion Programs: From Theory to Practice. San Francisco: Jossey-Bass Press; c2010. 61-67. 
[19] Hupcey JE. Clarifying the social support theoryresearch linkage. Journal of Advanced Nursing [Internet]. 1998;27(6):1231-1241. Available from: https://doi.org/10.1046/j.1365-2648.1998.01231.x

[20] Gupta AK, Sahoo S, Mehra A, Grover S. Psychological impact of "Lockdown" due to COVID-19 pandemic in Nepal: An online survey. Asian Journal of Psychiatry [Internet]. 2020;54:102243. Available from: https://doi.org/10.1016/j.ajp.2020.102243

[21] Wu JT, Leung K, Leung GM. Nowcasting and forecasting the potential domestic and international spread of the 2019-nCoV outbreak originating in Wuhan, China: a modelling study. The Lancet
[Internet]. 2020;395(10225):689-697. Available from: https://doi.org/10.1016/S0140-6736(20)30260-9

[22] Li S, Wang Y, Xue J, Zhao N, Zhu T. The impact of COVID-19 epidemic declaration on psychological consequences: a study on active weibo users. International Journal of Environmental Research and Public Health [Internet]. 2020;17(6):2032. Available from: https://doi.org/10.3390/ijerph17062032

Received: $2021-03-25$

Revised: 2021-04-28

Accepted: 2021-04-30 